\title{
A Small UWB Antenna with Dual Band-Notched Characteristics
}

\author{
J. Xu, ${ }^{1}$ D.-Y. Shen, ${ }^{1}$ G.-T. Wang, ${ }^{1}$ X.-H. Zhang, ${ }^{1}$ X.-P. Zhang, ${ }^{2}$ and K. Wu ${ }^{3}$ \\ ${ }^{1}$ School of Information Science and Engineering, Yunnan University, Kunming 650091, China \\ ${ }^{2}$ Department of Electrical and Computer Engineering, Concordia University, Montreal, QC, Canada \\ ${ }^{3}$ Department of Electrical Engineering, Université de Montréal, Montreal, QC, Canada \\ Correspondence should be addressed to D.-Y. Shen, shendy@ynu.edu.cn
}

Received 15 February 2012; Accepted 21 June 2012

Academic Editor: Hala A. Elsadek

Copyright ( $\odot 2012$ J. Xu et al. This is an open access article distributed under the Creative Commons Attribution License, which permits unrestricted use, distribution, and reproduction in any medium, provided the original work is properly cited.

\begin{abstract}
A small novel ultrawideband (UWB) antenna with dual band-notched functions is proposed. The dual band rejection is achieved by etching two C-shaped slots on the radiation patch with limited area. A single band-notched antenna is firstly presented, and then an optimized dual band-notched antenna is presented and analyzed. The measured VSWR shows that the proposed antenna could operate from 3.05 to $10.7 \mathrm{GHz}$ with VSWR less than 2, except two stopbands at 3.38 to $3.82 \mathrm{GHz}$ and 5.3 to $5.8 \mathrm{GHz}$ for filtering the WiMAX and WLAN signals. Radiation patterns are simulated by HFSS and verified by CST, and quasiomnidirectional radiation patterns in the $\mathrm{H}$-plane could be observed. Moreover, the proposed antenna has a very compact size and could be easily integrated into portable UWB devices.
\end{abstract}

\section{Introduction}

Since the Federal Communication Commission (FCC) allocated the frequency band $3.1-10.6 \mathrm{GHz}$ for commercial ultrawideband (UWB) systems, considerable research efforts have been put into UWB radio technology in industry and academia. Several UWB antennas with compact size have been reported in [1-3] recently. However, UWB systems have encountered a hostile radio environment which may cause potential interferences to the UWB band. For instance, IEEE 802.16 WiMAX system operates at $3.3-3.7 \mathrm{GHz}$ and IEEE 802.11 a WLAN system operates at $5.15-5.825 \mathrm{GHz}$. In some cases, UWB antennas use filters to avoid interferences. However, the use of filters increases the complexity and cost of the UWB system. Thus, antenna-filtering technique may be one of the simple, effective, and inexpensive methods, and antennas with small size and band rejection functions are desirable. In order to design UWB antennas with bandnotched functions, several methods have been proposed, including etching C-shaped, L-shaped, T-shaped, H-shaped, U-shaped, E-shaped, and half-circle slots on the radiation patch or on the ground plane [4-14]. Besides, by employing T-shaped, L-shaped, and spiral parasitic strips, bandrejection functions could be obtained [15-20]. By etching slots and employing parasitic strips at the same time [21, 22], dual band-notched functions could be achieved.
In this paper, a small novel ultrawideband antenna with dual band-notched characteristics is proposed and investigated in detail. The primitive UWB antenna has a compact size of $22 \mathrm{~mm} \times 18 \mathrm{~mm} \times 1.5 \mathrm{~mm}$. By etching a $\mathrm{C}$-shaped slot on the radiation patch, a single band-notched UWB antenna is first designed. By adding another C-shaped slot on the radiation patch, a small dual band-notched antenna has been successfully designed. It is observed from the simulated and measured VSWR that the proposed dual band-notched antenna could operate from 3.05 to $10.7 \mathrm{GHz}$ with VSWR less than 2, except two stopbands at 3.38 to $3.82 \mathrm{GHz}$ and 5.3 to $5.8 \mathrm{GHz}$ for filtering the WiMAX and WLAN signals. In addition, the proposed antenna has a nearly omnidirectional radiation patterns at the H-plane across the operating frequency band, which makes it a good candidate for UWB devices.

\section{Single Band-Notched UWB Antenna Design and Results}

A $3.5 \mathrm{GHz}$ single band-notched UWB antenna is firstly designed, and the specific geometry is shown in Figure 1. The substrate of the antenna is FR4 with a thickness of hsub $=1.5 \mathrm{~mm}$ and relative dielectric constant of 4.5 . An SMA connector is connected to the $50 \Omega$ microstrip feed line to feed the antenna. The radiation patch has a 


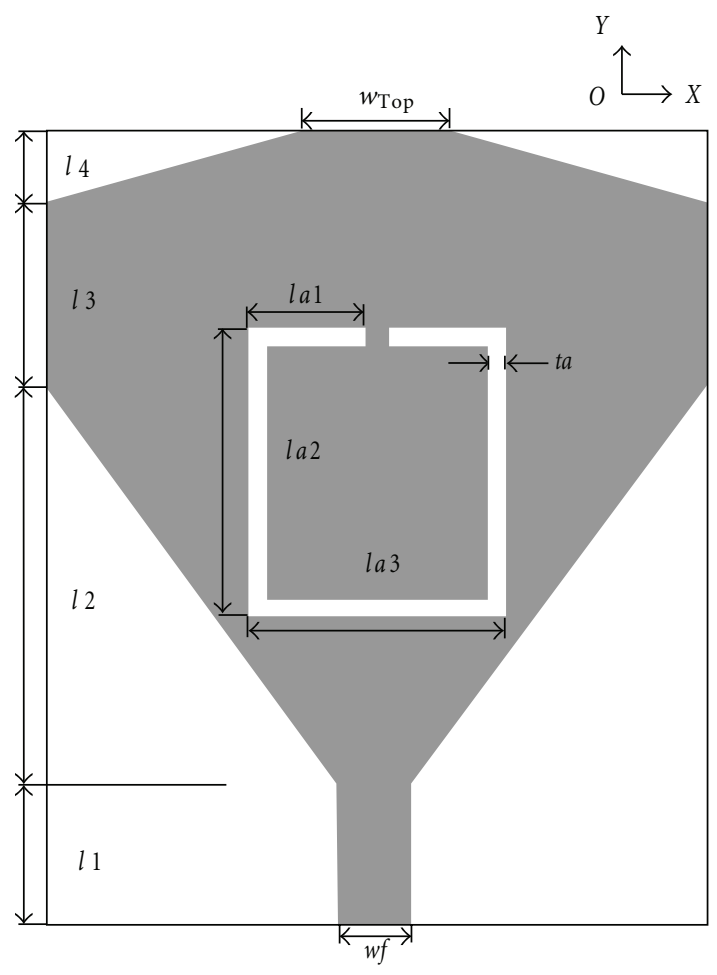

(a)

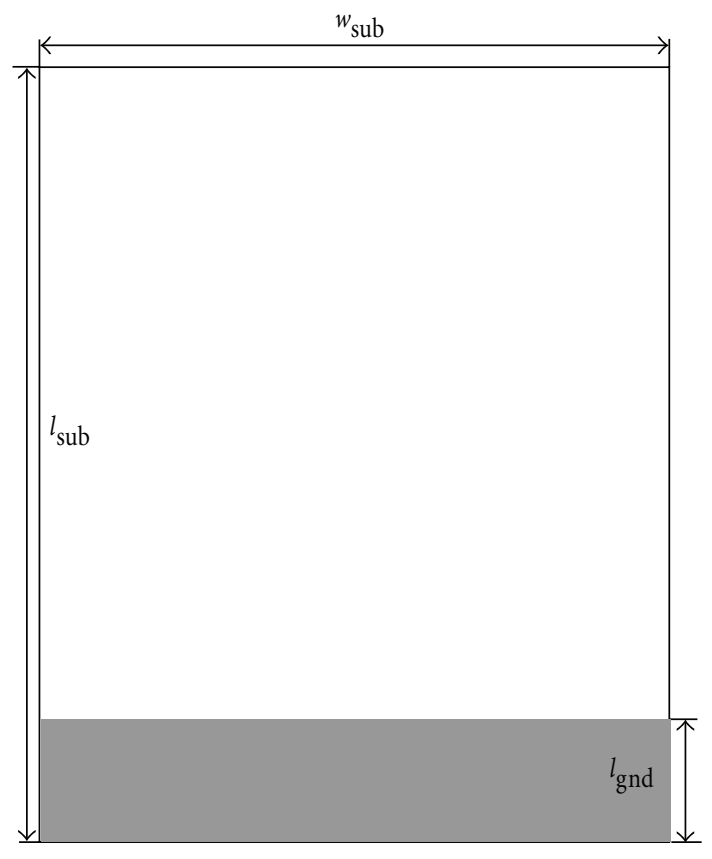

(b)

Figure 1: Geometry of single band-notched antenna. (a) Top view, (b) bottom view.

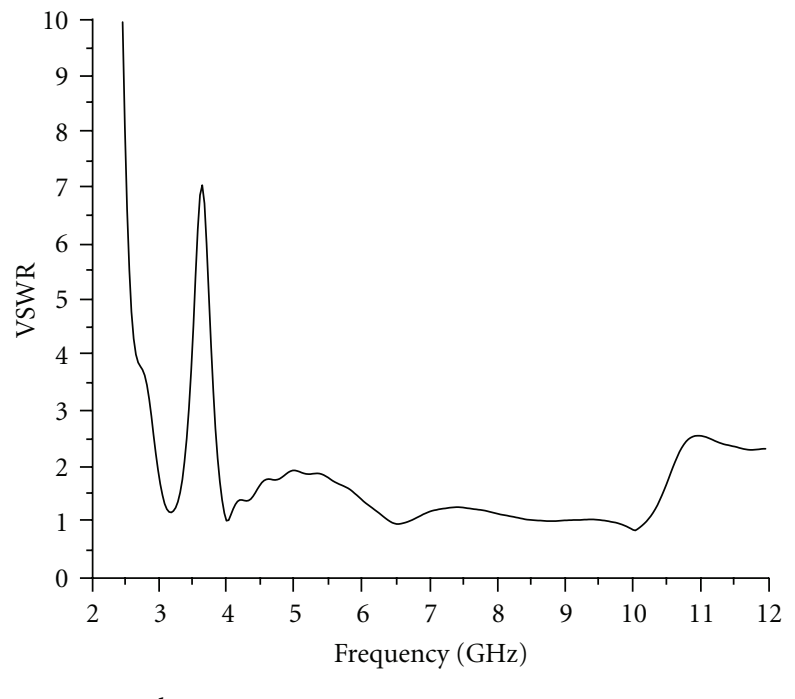

$-l a=29.4 \mathrm{~mm}$

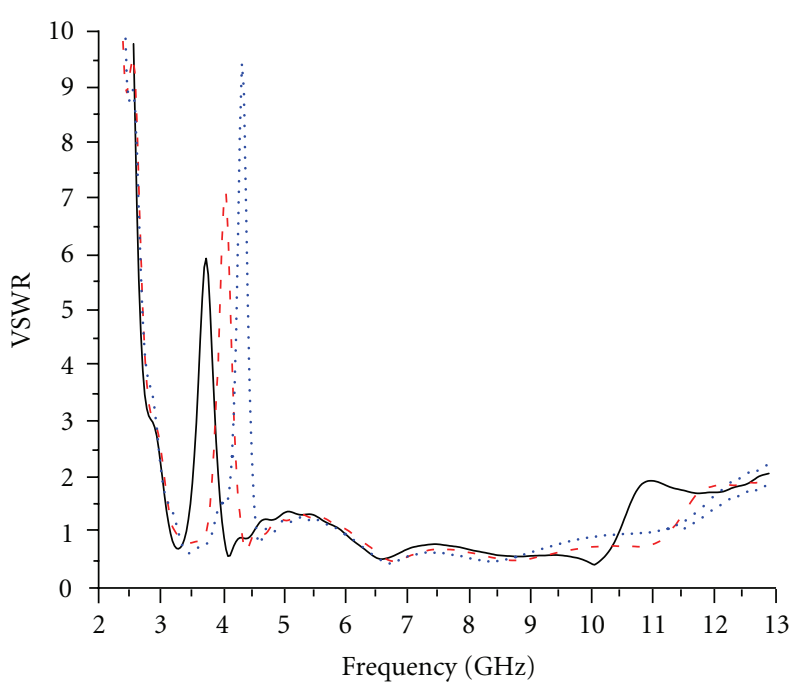

$\begin{aligned}-l a & =29.4 \mathrm{~mm} \\ \ldots-l a & =27.4 \mathrm{~mm} \\ \ldots . \quad l a & =25.4 \mathrm{~mm}\end{aligned}$

(a)

(b)

FIgURE 2: Simulated VSWR of single band-notched antenna with (a) optimized la, (b) different la.

shovel-shaped structure, and the dimensions are optimized using commercial software CST and HFSS. In order to eliminate interferences from IEEE 802.16 WiMAX system linebreak operating at $3.3-3.7 \mathrm{GHz}$, a C-shaped slot is etched on the patch to generate band rejection function. The notched frequency generated by the C-shaped slot can be postulated as

$$
f_{\text {notch }}=\frac{c}{2 L \cdot \sqrt{\varepsilon_{\text {eff }}}}
$$




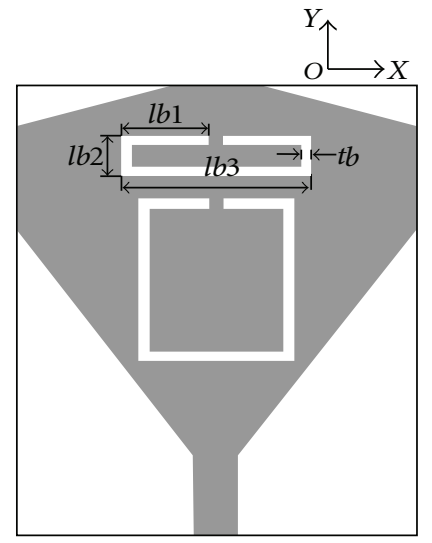

(a)

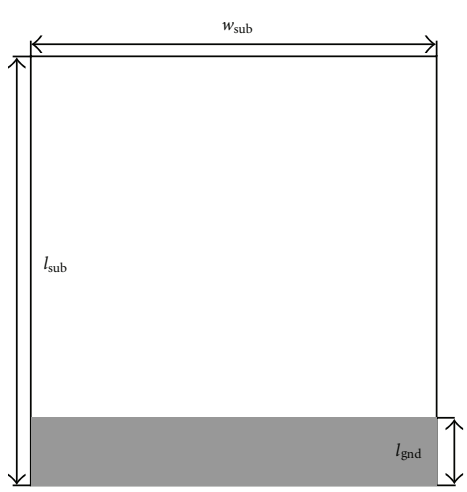

(b)

Figure 3: Geometry of dual band-notched antenna. (a) Top view, (b) bottom view.

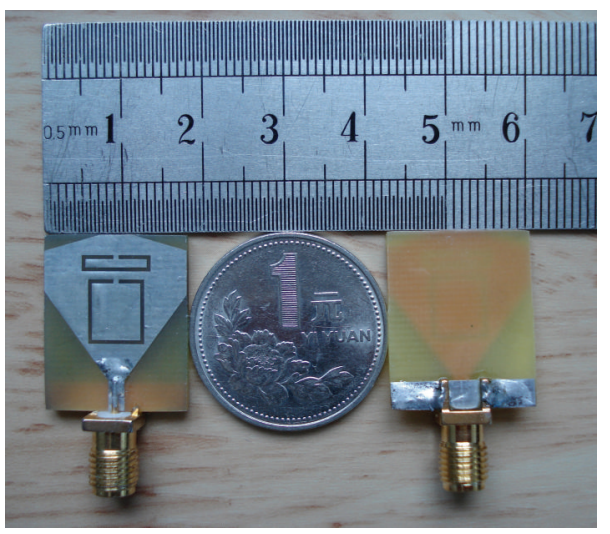

FIGURE 4: Photograph of the proposed dual band-notched antenna.

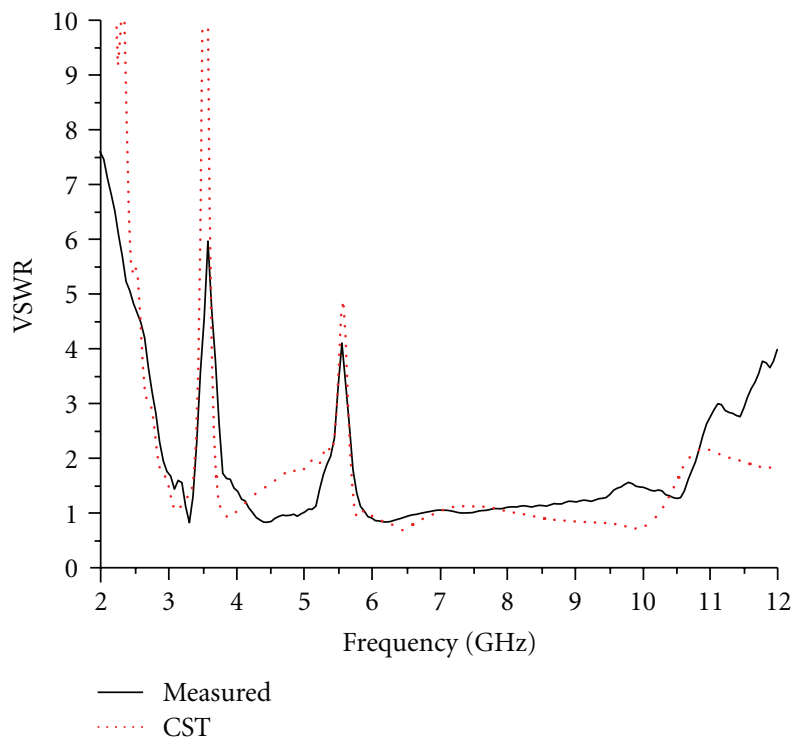

FIGURE 5: Simulated and measured VSWR of the proposed dual band-notched antenna.

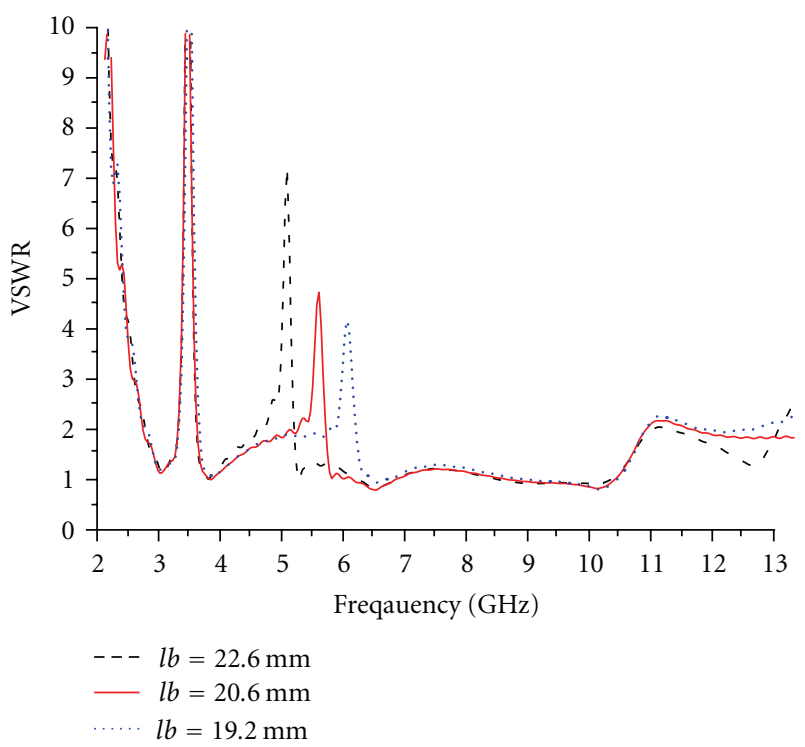

Figure 6: Effects of parameter $l b$ on the $5.5 \mathrm{GHz}$ band-notch function.

TABLE 1: Optimized parameters of the single band-notched antenna.

\begin{tabular}{lccccccc}
\hline Parameters & $w_{\text {sub }}$ & $l_{\text {sub }}$ & $l_{\text {gnd }}$ & $h_{\text {sub }}$ & $l 1$ & $l 2$ & $l 3$ \\
\hline Value $(\mathrm{mm})$ & 18 & 22 & 3.5 & 1.5 & 4 & 11 & 5 \\
Parameters & $l 4$ & $l a 1$ & $l a 2$ & $l a 3$ & $t a$ & $w_{\text {Top }}$ & $w_{\mathrm{f}}$ \\
Value $(\mathrm{mm})$ & 2 & 3.2 & 8 & 7 & 0.5 & 4 & 2 \\
\hline
\end{tabular}

where $L$ is the total length of the C-shaped slot, $\varepsilon_{\text {eff }}$ is the effective dielectric constant, and $c$ is the speed of light. The position, length, and width of the slot have great effects on the band rejection performance and should be tuned carefully. Note that when the C-shaped slot is etched on the radiation patch, there is no retuning work needed for the primitive antenna structure. The optimized parameters of the antenna geometry are listed in Table 1. 


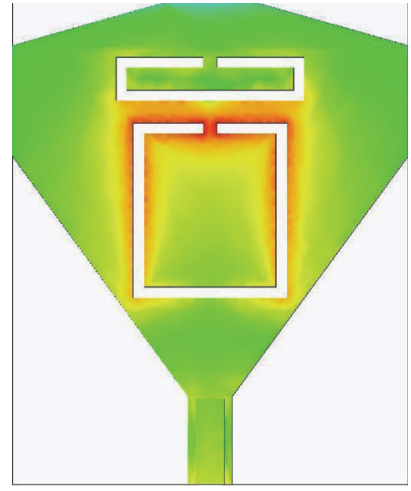

(a)

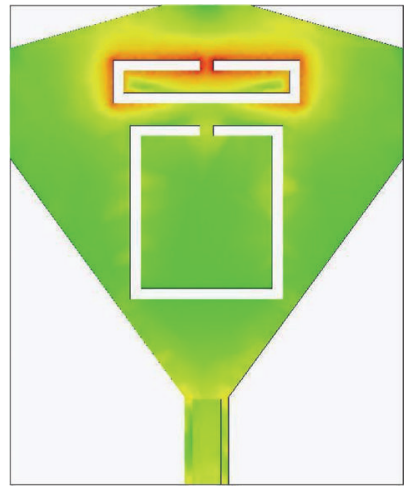

(b)

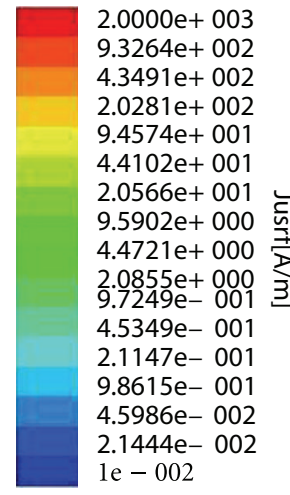

$1 \mathrm{e}-002$

FIgURE 7: Simulated current distribution of the proposed antenna. (a) $3.5 \mathrm{GHz}$, (b) $5.5 \mathrm{GHz}$.

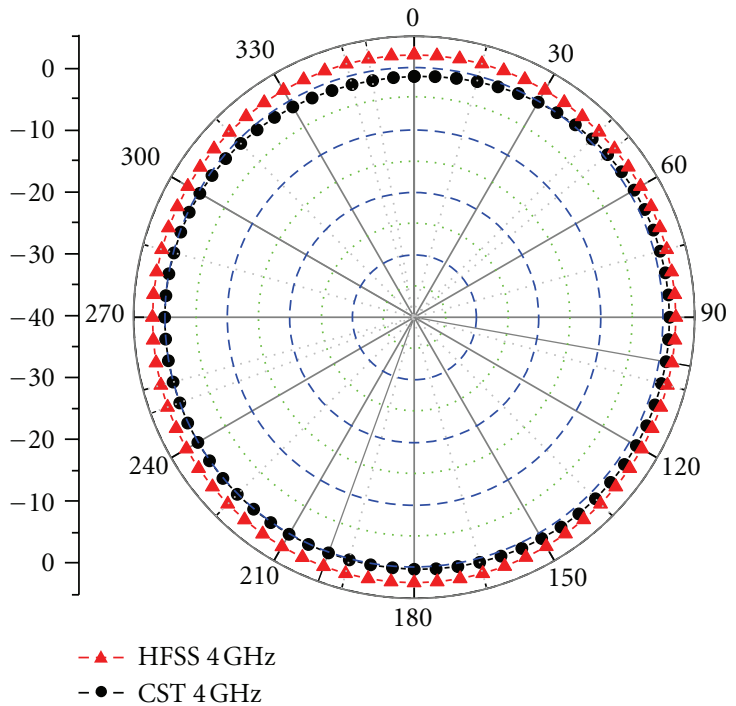

(a)

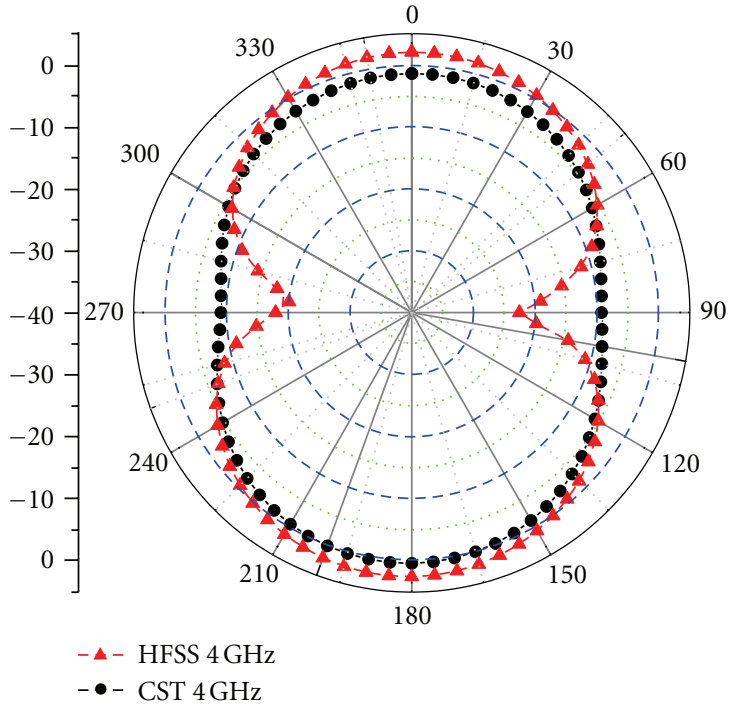

(b)

FIGURE 8: Radiation patterns of the proposed antenna at $4 \mathrm{GHz}$; (a) xoz-plane, (b) yoz-plane.

The simulated VSWR of the single band-notched antenna is shown in Figure 2. It could be observed that this antenna could operate from 2.95 to $10.68 \mathrm{GHz}$ with VSWR less than 2 , except one stopband from 3.35 to $3.85 \mathrm{GHz}$. Let $l a=2 \times$ $l a 1+2 \times l a 2+l a 3$; the simulated VSWR for different $l a$ is given in Figure 2(b). By decreasing la from 29.4 to $25.4 \mathrm{~mm}$, the notched frequency is shifted up from 3.6 to $4.2 \mathrm{GHz}$.

\section{Dual Band-Notched UWB Antenna}

3.1. Antenna Design and Configuration. Besides WiMAX systems, WLAN operating from 5.15 to $5.825 \mathrm{GHz}$ may cause interferences to the UWB system too. By etching another smaller C-shaped slot on the radiation patch, $5.5 \mathrm{GHz}$ band-notched function is realized. The notched frequency generated by the C-shaped slot can be postulated by (1). The specific geometry of the dual band-notched antenna is shown in Figure 3. All the dimensions are the same as that in Figure 1, except the adding of another smaller C-shaped slot. The geometry of the smaller slot is given in Table 2. An alternative method to generate dual band-notched function is using two nested C-shaped slots [4], but the tuning process may be complicated due to mutual coupling of the slots. Thus, two independent C-shaped slots are used to generate dual band-notched functions and the tuning process could be simplified.

3.2. Simulated and Measured Results and Discussions. In order to verify the design concept, a prototype of the dual band-notched antenna is fabricated and measured. The photograph of the fabricated dual band-notched antenna is given in Figure 4. The VSWR of the dual band-notched antenna is measured by Agilent E8364B Vector Network Analyzer and is given in Figure 5. Relatively good agreement between the simulated and measured VSWR could be observed. The discrepancy is mainly due to the fabrication tolerance and hand welding inaccuracy. It could be observed that the designed antenna has a wideband performance of 


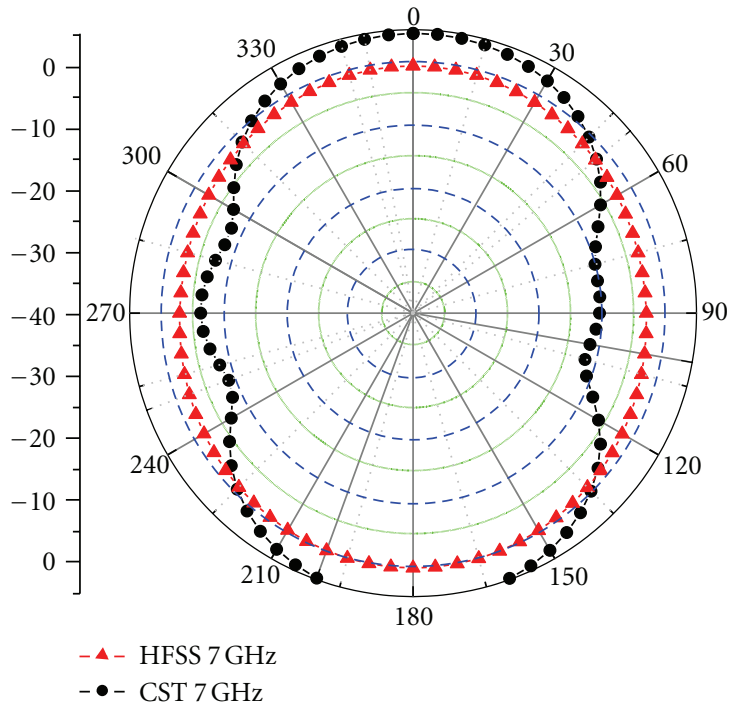

(a)

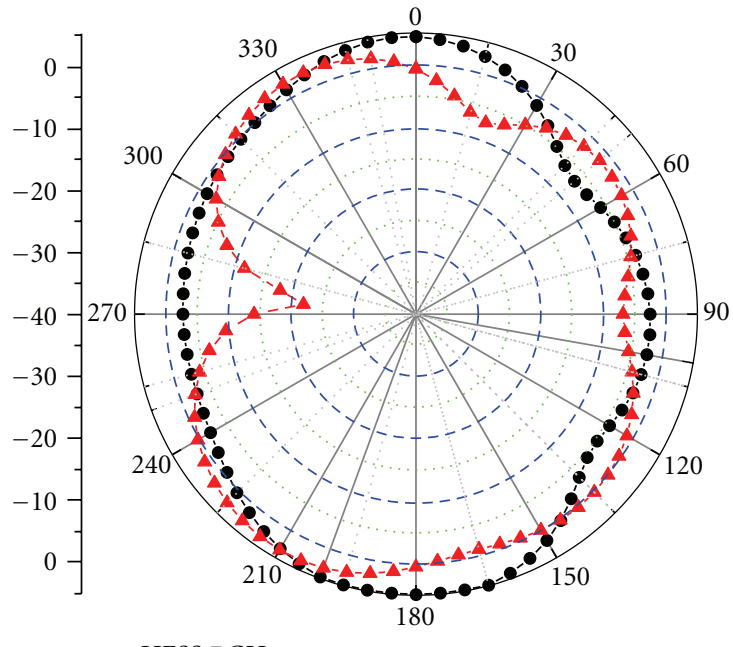

- - HFSS $7 \mathrm{GHz}$

- - CST $7 \mathrm{GHz}$

Figure 9: Radiation patterns of the proposed antenna at $7 \mathrm{GHz}$; (a) xoz-plane, (b) yoz-plane.

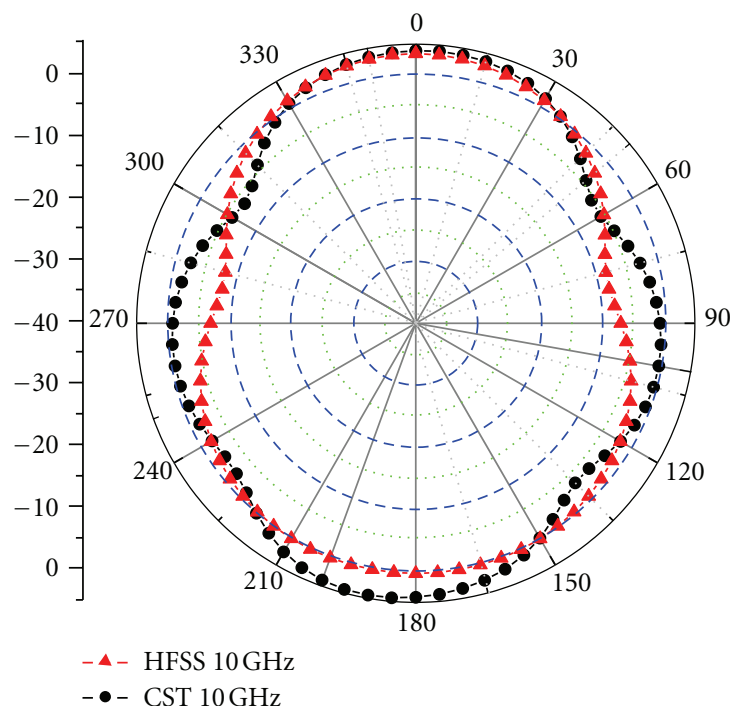

(a)

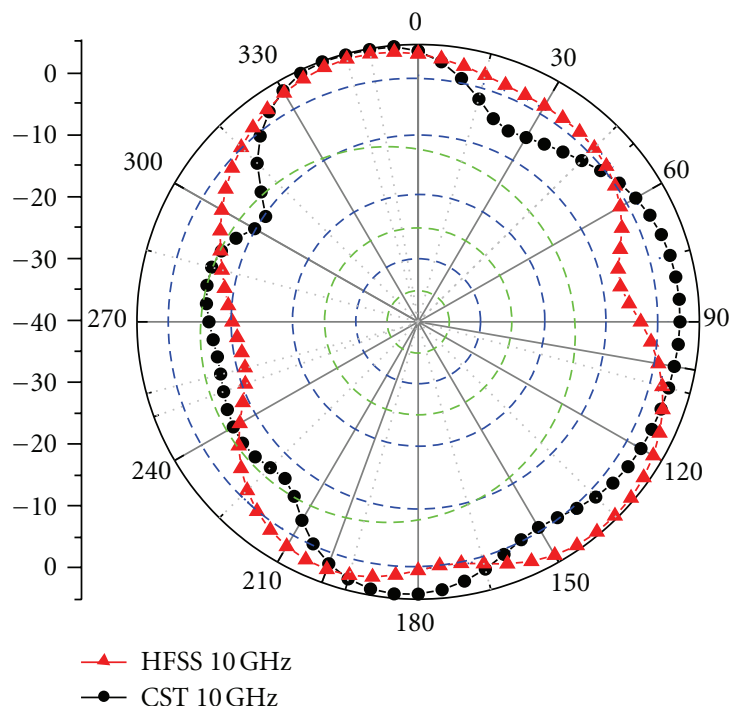

(b)

Figure 10: Radiation patterns of the proposed antenna at $10 \mathrm{GHz}$; (a) xoz-plane, (b) yoz-plane.

TABLE 2: Optimized geometry of the smaller C-shaped slot.

\begin{tabular}{lcccc}
\hline Parameters & $l b 1$ & $l b 2$ & $l b 3$ & $t b$ \\
\hline Value $(\mathrm{mm})$ & 4 & 2 & 8.6 & 0.5 \\
\hline
\end{tabular}

3.05-10.7 GHz for VSWR less than 2, covering the entire UWB frequency band, with two stopbands at 3.38-3.82 GHz and 5.3-5.8 GHz for filtering the WiMAX and WLAN signals.

Let $l b=2 \times l b 1+2 \times l b 2+l b 3$; effects of parameter $l b$ on the $5.5 \mathrm{GHz}$ band-notched function is simulated and is shown in Figure 6 . Note that the tuning of parameter $l b$ has little affection on the VSWR of the dual band-notched antenna throughout the whole UWB frequency range, except the $5.5 \mathrm{GHz}$ stopband. Thus, the $5.5 \mathrm{GHz}$ band-notched characteristic could be tuned independently and no retuning work is needed for the antenna structure. It is observed that by decreasing $l b$ from 22.6 to $19.2 \mathrm{~mm}$, the notched frequency is shifted up from 5.1 to $6.0 \mathrm{GHz}$.

The simulated surface current distributions at $3.5 \mathrm{GHz}$ and $5.5 \mathrm{GHz}$ are given in Figure 7. The large current distribution is indicated in red, and small one is in blue. It is observed that the surface current is highly concentrated at each C-shaped slot, which means that a large portion of 


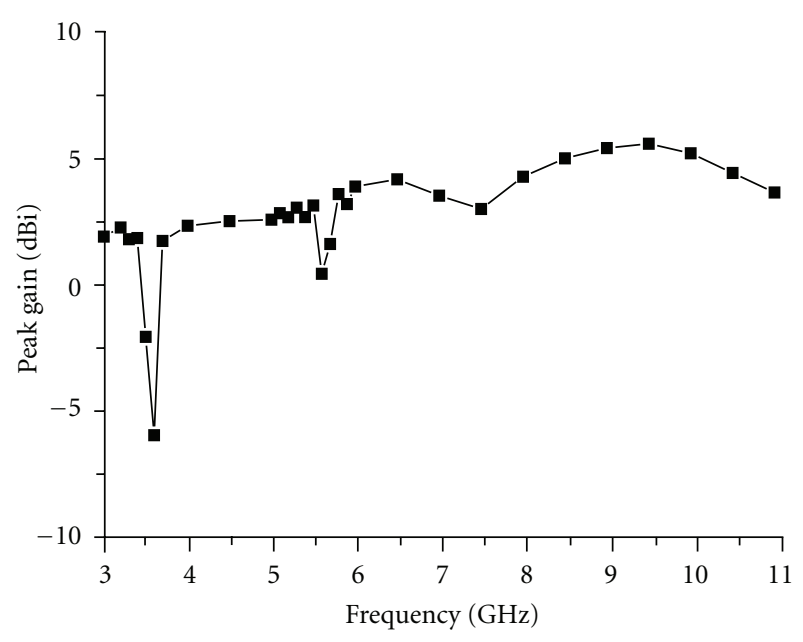

Figure 11: Peak gain of the proposed antenna.

electromagnetic energy has been stored around the slots and the radiation efficiency decreases at the rejected band.

The simulated radiation patterns at xoz-plane (H-plane) and yoz-plane (E-plane) of the proposed antenna at $4 \mathrm{GHz}$, $7 \mathrm{GHz}$, and $10 \mathrm{GHz}$ are illustrated in Figures 8, 9, and 10, respectively. It is observed that the radiation patterns at xozplane are nearly omnidirectional, which makes it a good candidate for UWB devices.

Furthermore, Figure 11 shows the peak gain of the proposed dual band-notched antenna. The simulated peak gain ranges from 2 to $5.5 \mathrm{dBi}$ throughout the whole UWB frequency band, except two stopbands. As discussed above, the energy at the notched frequency bands is not radiated so that the radiation efficiency drops at the notched frequency bands. Thus, the peak gain decreases sharply at $3.5 \mathrm{GHz}$ and $5.5 \mathrm{GHz}$, which clearly indicates the dual band rejection functions of the proposed antenna.

\section{Conclusions}

In this paper, a small novel UWB antenna with dual bandnotched characteristics has been proposed and analyzed. The primitive UWB antenna is fabricated on FR4 substrate and has a shovel-shaped radiation patch, which results in a compact size of $22 \mathrm{~mm} \times 18 \mathrm{~mm} \times 1.5 \mathrm{~mm}$. Two C-shaped slots are etched on the small patch to achieve $3.5 \mathrm{GHz}$ and $5.5 \mathrm{GHz}$ dual band-notched functions. Nearly omnidirectional radiation patterns could be observed at the $\mathrm{H}$-plane throughout the whole operating frequency band. Accordingly, the proposed dual band-notched UWB antenna might be useful for compact portable UWB devices to eliminate abundant electromagnetic interferences.

\section{Acknowledgments}

This work was supported in part by the National Science and Technology Major Project (no. 2010ZX03007-001) and the Key Project of International Cooperation of Yunnan Province (no. 2009AC010).

\section{References}

[1] Z.-A. Zheng and Q.-X. Chu, "CPW-fed ultra-wideband antenna with compact size," Electronics Letters, vol. 45, no. 12, pp. 593-594, 2009.

[2] A. A. Shaalan and M. I. Ramadan, "Design of a compact hexagonal monopole antenna for ultra-wideband applications," Journal of Infrared, Millimeter, and Terahertz Waves, vol. 31, no. 8, pp. 958-968, 2010.

[3] Z.-N. Chen, T. S. P. See, and X.-M. Qing, "Small printed ultrawideband antenna with reduced ground plane effect," IEEE Transactions on Antennas and Propagation, vol. 55, no. 2, pp. 383-388, 2007.

[4] Q.-X. Chu and Y.-Y. Yang, "A compact ultrawideband antenna with $3.4 / 5.5 \mathrm{GHz}$ dual band-notched characteristics," IEEE Transactions on Antennas and Propagation, vol. 56, no. 12, pp. 3637-3644, 2008.

[5] A. Edalati and T. A. Denidni, "A compact uwb antenna with dual band-notched characteristics," Microwave and Optical Technology Letters, vol. 52, no. 5, pp. 1183-1186, 2010.

[6] M. T. Islam, A. T. Mobashsher, and N. Misran, "Coplanar waveguide fed printed antenna with compact size for broadband wireless applications," Journal of Infrared, Millimeter, and Terahertz Waves, vol. 31, no. 12, pp. 1427-1437, 2010.

[7] O. M. H. Ahmed and A. R. Sebak, "A novel maple-leaf shaped UWB antenna with a 5.0-6.0 GHz band-notch characteristic," Progress in Electromagnetics Research C, vol. 11, pp. 39-49, 2009.

[8] R. Movahedinia and M. N. Azarmanesh, "A novel planar UWB monopole antenna with variable frequency band-notch function based on etched slot-type ELC on the patch," Microwave and Optical Technology Letters, vol. 52, no. 1, pp. 229-232, 2010.

[9] S.-F. Niu, G.-P. Gao, M. Li, Y.-S. Hu, and B.-N. Li, "Design of a novel elliptical monopole UWB antenna with dual bandnotched function," Microwave and Optical Technology Letters, vol. 52, no. 6, pp. 1306-1310, 2010.

[10] H.-L. Zhang, R.-G. Zhou, Z.-R. Wu, H. Xin, and R. W. Ziolkowski, "Designs of ultra wideband (UWB) printed elliptical monopole antennas with slots," Microwave and Optical Technology Letters, vol. 52, no. 2, pp. 466-471, 2010.

[11] M. Ojaroudi, G. Ghanbari, N. Ojaroudi, and C. Ghobadi, "Small square monopole antenna for UWB applications with variable frequency band-notch function," IEEE Antennas and Wireless Propagation Letters, vol. 8, pp. 1061-1064, 2009.

[12] X.-F. Zhu and D.-L. Su, "Symmetric E-shaped slot for UWB antenna with band-notched characteristic," Microwave and Optical Technology Letters, vol. 52, no. 7, pp. 1594-1597, 2010.

[13] M. A. Habib, A. Bostani, A. Djaiz, M. Nedil, M. C. E. Yagoub, and T. A. Denidni, "Ultra wideband cpw-fed aperture antenna with wlan band rejection," Progress in Electromagnetics Research, vol. 106, pp. 17-31, 2010.

[14] S. Barbarino and F. Consoli, "UWB circular slot antenna provided with an inverted-L notch filter for the $5 \mathrm{GHz}$ WLAN band," Progress in Electromagnetics Research, vol. 104, pp. 113, 2010.

[15] R. Fallahi, A.-A. Kalteh, and M.-G. Roozbahani, "A novel UWB elliptical slot antenna with band-notched characteristics," Progress in Electromagnetics Research, vol. 82, pp. 127136, 2008.

[16] T.-F. Xia, S.-W. Yang, and Z.-P. Nie, "Band-notched UWB planar antenna with parasitic spiral strips," Microwave and Optical Technology Letters, vol. 53, no. 7, pp. 1532-1535, 2011. 
[17] W.-X. Liu and Y.-Z. Yin, "Dual band-notched antenna with the parasitic strip for UWB," Progress in Electromagnetics Research Letters, vol. 25, pp. 21-30, 2011.

[18] R. Rouhi, C. Ghobadi, J. Nourinia, and M. Ojaroudi, "Microstrip-fed small square monopole antenna for UWB application with variable band-notched function," Microwave and Optical Technology Letters, vol. 52, no. 9, pp. 2065-2069, 2010.

[19] G.-P. Gao, M. Li, S.-F. Niu, X.-J. Li, B.-N. Li, and J.-S. Zhang, "Study of a novel wideband circular slot antenna having frequency band-notched function," Progress in Electromagnetics Research, vol. 96, pp. 141-154, 2009.

[20] K. S. Ryu and A. A. Kishk, "UWB antenna with single or dual band-notches for lower WLAN band and upper WLAN band," IEEE Transactions on Antennas and Propagation, vol. 57, no. 12, pp. 3942-3950, 2009.

[21] C.-M. Li and L.-H. Ye, "Improved dual band-notched uwb slot an-tenna with controllable notched band-widths," Progress in Electromagnetics Research, vol. 115, pp. 477-493, 2011.

[22] W.-T. Li, X.-W. Shi, T.-L. Zhang, and Y. Song, "Novel UWB planar monopole antenna with dual band-notched characteristics," Microwave and Optical Technology Letters, vol. 52, no. 1, pp. 48-51, 2010. 

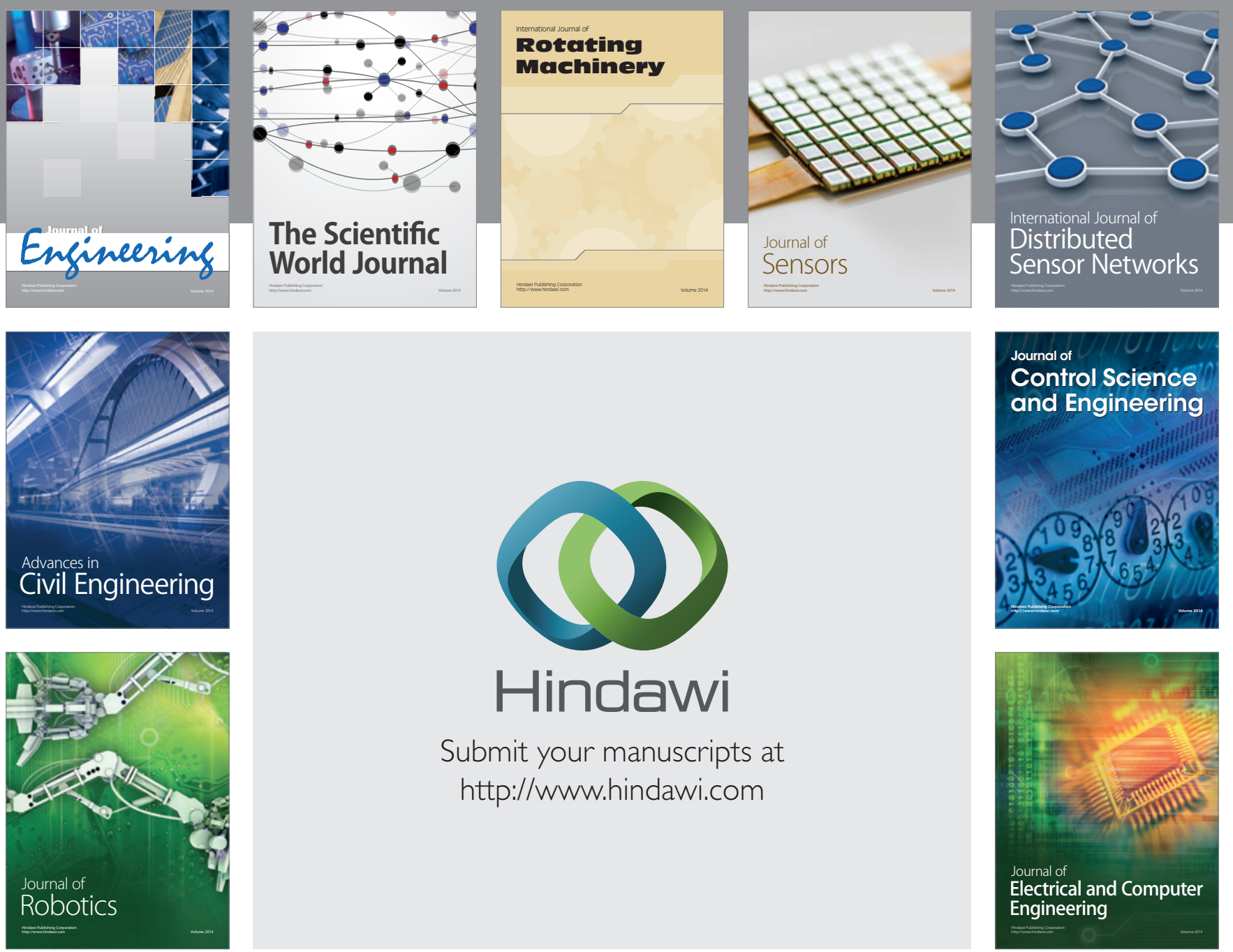

Submit your manuscripts at

http://www.hindawi.com
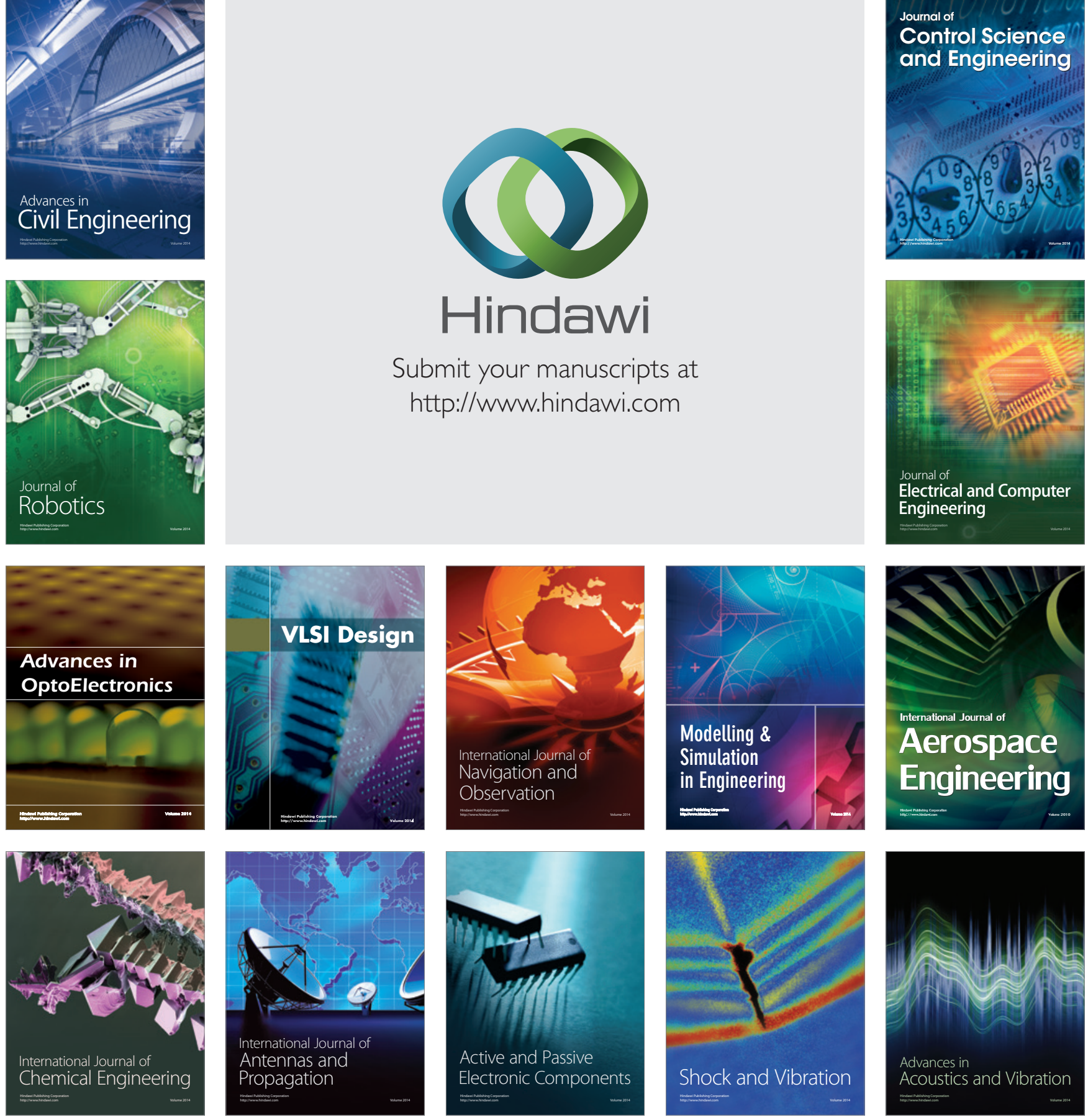